\title{
Self-directed Strength Training with Primary School Children and its Effect on Functional Body-related Knowledge
}

\author{
Nico Nitzsche (Corresponding author) \\ Institute of Human Movement Science and Health, Chemnitz University of Technology \\ 09130, Chemnitz, Germany \\ E-mail: nico.nitzsche@hsw.tu-chemnitz.de \\ Toni Lange \\ University Hospital Carl Gustav Carus Dresden, Center for Evidence Based Healthcare, \\ 01307, Dresden, Germany \\ E-mail: Toni.Lange@uniklinikum-dresden.de \\ Markus Klein \\ Institute for Sport Science, Saarland University \\ 66123, Saarbrücken, Germany \\ E-mail: ma.klein@mx.uni-saarland.de \\ Michael Fröhlich \\ Department for Sport Science, Kaiserslautern University of Technology \\ 67663, Kaiserslautern, Germany \\ E-mail: michael.froehlich@sowi.uni-kl.de
}

Received: 11-03- 2015

doi:10.7575/aiac.ijkss.v.3n.2p.22
Accepted: 26-04- 2015

Published: 30-04- 2015

URL: http://dx.doi.org/10.7575/aiac.ijkss.v.3n.2p.22

\begin{abstract}
Introduction: Strength training intervention is primarily controlled by training parameters. A scientific desideratum exists concerning the question to what extent a self-controlled load perception might have an effect on motor performance and functional body-related knowledge. Method: A total of 81 primary school students were assigned to an intervention group $(\mathrm{N}=34,9.7 \pm 2$ years) and control group $(\mathrm{N}=47,7.3 \pm 0.4$ years). The intervention group performed strength training twice a week (circuit training, scope of load: 45-60 minutes, duration 20-30 seconds, 7 stations, rest between sets 20-30 seconds, self-regulated intensity). After 9 weeks, both groups were tested for motor performance and functional body-related knowledge. Results: For push-ups (PRETEST: Z=103.2 \pm 7 vs. POSTTEST: Z=114.7 \pm 9 ; $\mathrm{d}=1.4 ; P<0.01$ ) and sit-ups (PRETEST: $\mathrm{Z}=90.9 \pm 8$ vs. POSTTEST: $\mathrm{Z}=98.6 \pm 9 ; \mathrm{d}=0.89 ; \quad P<0.01$ ), a significant improvement was established in the intervention group. The control group showed substantial improvement for pushups (PRETEST: $\mathrm{Z}=101.8 \pm 10$ vs. POSTTEST: $\mathrm{Z}=107.5 \pm 9 ; \mathrm{d}=0.58 ; P<0.01$ ) and significant decline for sit-ups (PRETEST: $Z=99.1 \pm 7$ vs. POSTTEST: $Z=96.6 \pm 6 ; \mathrm{d}=-0.36 ; P<0.05)$. As to the knowledge test, the intervention group increased their performance considerably (PRETEST: $35 \pm 2$ points vs. POSTTEST: $40 \pm 4$ points; $\mathrm{d}=0.9 ; P<0.01$ ) when compared to the control group (PRETEST: $34.2 \pm 4.6$ points vs. POSTTEST: $31.2 \pm 4.5$ points; $\mathrm{d}=-0.69 ; P<0.01$ ). Discussion: A nine-week, self-regulated strength training for children has positive effects on sport motor performance (push-ups and sit-ups) and functional body-related knowledge.
\end{abstract}

Keywords: Strength training, children, motor performance, functional body-related knowledge, self-controlled load perception

\section{Introduction}

On the one hand, targeted fitness development at an early age, especially in childhood and adolescence, is deemed the basis for leading an active lifestyle, avoiding potential overweight, reducing motor deficiencies, and thus improving the general quality of life (Fogelholm, 2010; Raj, 2012). On the other hand, the evidence of a general decline in motor performance, allegedly decreasing physical activity, and increased weight status has empirically not been conclusively determined (Klein, Fröhlich, \& Emrich, 2013; Klein, Fröhlich, Pieter, \& Emrich, 2015). It is relatively safe to say, however, that obesity in childhood significantly increases morbidity and mortality due to the growing risk factors (even though with weak effects), and that the fitness status can have a moderating influence (Fogelholm, 2010; Metcalf et al., 2011). The promotion of health competence is more and more encouraged, particularly in children (Raj, 2012). The basis for self-controlled and responsible design of their own health resources is to be created as early as possible. For adults, the term of health competence has been established over the past years: essential abilities and skills, physical and 
movement-related basic knowledge, useful personal characteristics, as well as health-related evaluation dispositions represent the basis of health competence. Pfeifer, Sudeck, Geidl, and Tallner (2013) have been observing movementrelated health competence, mainly focusing on the aspect that specific target groups exercise and behave in healtheffective ways in the long term. Movement-related health competence builds on knowledge, ability, and willingness, and it addresses the individual's motor preconditions. It can be generated through learning motor skills, relaying action knowledge (effect and action), and implementing self-control. For this, appropriate movement interventions inducing body-related knowledge through movement experience need to be tested. In addition to ball sports and racquet sports, which are already established in school routine, educational strength training could represent a measure to ensure early motor development. For quite some time, it has been called for to develop health competence in children as early as practicable. Basic approaches pertaining to health-related knowledge already exist, and the children are able to assess their state of health. The knowledge about the effect of sports and body functions may be relevant in this respect. It is already known that children and adolescents, who have been active in sports that require a high degree of technicalcoordinative movement at an early age, exhibit pronounced, distinctive body awareness. In contrast to sports games with a focus on the sports equipment, the focus set on the extremities in strength training can school the intrinsic awareness of muscle function. Preventive and performance-promoting effects are expected when applying child- and age-oriented strength training. Considering the aspect of subjectively perceived exertion in strength training, studies within the context of school sports have been conducted with positive results.

Risk of injury caused by strength training in children and adolescents is currently to be deemed low and compared to other sports or disciplines, even marginal (Faigenbaum \& Myer, 2010). For most of the study results, strength training related hypertrophy effects in the sense of muscle mass increase can be assumed to be negligible because strength training effects are mostly due to neuromuscular adjustment processes, particularly at the beginning of systematic exercising (Falk \& Tenenbaum, 1996; Granacher et al., 2011; Payne, Morrow, Johnson, \& Dalton, 1997). Nevertheless, positive effects in terms of body mass reduction and energy metabolism increase have been observed in children (Lillegard, Brown, Wilson, Henderson, \& Lewis, 1997; Westcott, Tolken, \& Wessner, 1995).

Furthermore, it has been shown that additive plyometric training increased various motor test performances, and training twice a week turned out to be superior to training once a week in terms of performance increases (Faigenbaum et al., 2009; Faigenbaum et al., 2007; Faigenbaum et al., 2002). Altogether, untrained children achieved a higher degree of strength increase if the exercises were performed with a higher number of repetitions (10-15 repetitions). So far, study results suggest a gender-independent, but age-dependent strength-increasing effect (Behringer, vom Heede, Yue, \& Mester, 2010). The comparison of effects regarding strength increase in percent is to be viewed as not unequivocal due to differently tested muscle groups (e.g., upper, lower extremities, or complex exercises) and test variants (e.g., 1 RM method, calculated maximum weight, isometric and isokinetic measurement). The effects of strength increase can be considered medium to very high (Faigenbaum \& Westcott, 2000). Data on strength increases in percent range between 13\% and 30\% on the one hand, and between 30\% and 50\% on the other (Lloyd et al., 2014; Payne et al., 1997).

Up to now, studies have rather focused on feasibility and implementation, as well as on the development of physical performance of children. These studies have been carried out in the form of stationary training with exact definitions of the load parameters, duration, concentration, and scope (Christou et al., 2006; Ingle, Sleap, \& Tolfrey, 2006; Lillegard et al., 1997; Shariat, Shariat, Abedi, \& Bahri, 2014). However, transfer effects pertaining to health-related functional body knowledge have not been examined yet. Therefore, the new approach of this study is to verify the extent to which self-controlled strength training has an effect on motor performance and functional body-related knowledge.

\section{Methods}

\subsection{Subjects}

A total of 81 primary school children of a small, rural town participated in the study (26.000 inhabitant, with 3 primary schools). The children were assigned to an intervention group and a control group (Table 1). The intervention group ( $\mathrm{N}=34 ; 18$ males and 16 females) and the control group ( $\mathrm{N}=47 ; 25$ males and 22 females) were tested regarding motor performance and functional body-related knowledge in an interval of 9 weeks. The study objectives had been explained to the children in writing and verbally, and the parents had provided their written consent to the children's participation in the study. The study was approved by the local ethics committee (IfS21042011).The study complied with ethical guidelines as outlined in the Declaration of Helsinki as well as with the ethical standards (Harriss \& Atkinson, 2011).

Table 1. Anthropometric data of the intervention and control groups

\begin{tabular}{llcccc}
\hline & & Age $[\mathbf{y}]$ & Weight $[\mathbf{k g}]$ & Height $[\mathbf{c m}]$ & BMI $\left[\mathbf{k g} / \mathbf{m}^{2}\right]$ \\
\hline Intervention & MEAN \pm SD & $9.7 \pm 2.0$ & $36.9 \pm 12.0$ & $140.3 \pm 14.1$ & $18.2 \pm 3.1$ \\
$\mathbf{N = 3 4}$ & MIN/MAX & $6.0 / 13.0$ & $20.3 / 63.6$ & $112.0 / 166.0$ & $12.9 / 26.5$ \\
\hline Control & MEAN \pm SD & $7.3 \pm 0.4$ & $26.2 \pm 5.4$ & $126.8 \pm 5.8$ & $16.1 \pm 2.3$ \\
$\mathbf{N = 4 7}$ & MIN/MAX & $6.5 / 8.5$ & $17.2 / 45.2$ & $116.0 / 145.0$ & $12.6 / 21.9$ \\
\hline
\end{tabular}

MEAN=mean value; $\mathrm{SD}=$ Standard Deviation; Min=Minimum value, Max=Maximum value 


\subsection{Measuring instruments}

To determine strength performance, the German motor performance tests (DMT 6-18) were employed (strength endurance: push-ups and sit-ups, explosive strength: standing long jump) (Bös et al., 2009). The absolute values (repetitions, jump distance) were transformed into Z-values and categorized into performance classes according to Bös et al. (2009). Instructions for the motor performance tests were given by trained testers (Klein et al., 2013). In order to obtain information on the scope of functional body-related knowledge, a test in the form of a questionnaire was developed. The questionnaire was divided into three topical areas. The first part (array 1) contained general questions on sports, behavior, and body responses. The second part (array 2) asked about functional relationships between movement and musculature. The third part (array 3) addressed the comprehension of training equipment and muscles to be trained (Table 2).

Table 2. Arrays of questions

\begin{tabular}{ll}
\hline Array & Question \\
\hline Array 1 & Is sweating while exercising healthy? \\
& Is pain during exercising healthy? \\
& Is drinking while exercising important? \\
& Is sport healthy? \\
& If I concentrate properly, my balancing is better. \\
\hline Array 2 & Which muscles bend your arms? \\
& Which muscles stretch your knees? \\
& Which muscle moves your head to the right? \\
& Which muscle enables you to get up on your toes? \\
\hline Array 3 & Which muscle presses the equipment down? \\
& Which muscle presses your body up? \\
& Which muscle bends your body forward? \\
\hline
\end{tabular}

The arrays of questions were not identified for the children. To eliminate reading and comprehension problems, the questionnaire was read to the participants, with the drawings being explained through a presentation of visual movement animation. Each child then selected the presumably correct answer. In order to keep the children focused, the test duration did not exceed 10 minutes. Answer options were "yes", "don't know", and "no". In the post test, the order of questions was changed to control the questions' recognition effect (Table 3).

Table 3. Sample questions from each array (1-3) with answer options (the correct answer is to be marked with an X)

\begin{tabular}{lll}
\hline $\mathbf{1}$ Is pain during exercising healthy? & \\
$\square$ Yes & & \\
\hline Don't know & $\square$ No \\
\hline
\end{tabular}

2 Which muscles bend your arms?
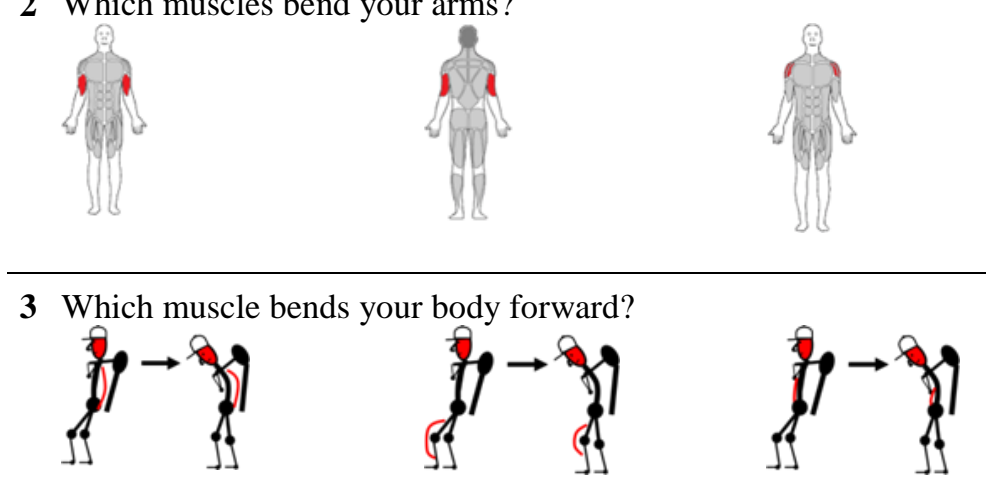

During the nine-week intervention, the intervention group performed dynamic strength training twice a week. A pretraining including two units was carried out for familiarizing purposes before the actual training phase. The organizational form selected was an circuit training (scope of load: 45-60 minutes, duration of load: 20-30 seconds, 7 stations, rest between sets: 20-30 seconds). During the first three weeks, two rounds of circuit training were performed, and from the fourth week on, three rounds of circuit training were performed each week. The exercise time was a predefined, fixed value. The children were to regulate the repetitions and weights in line with their subjective load 
perception (Borg, 1985). They were instructed to perceive the maximum load as exhausting. Scaling (Borg scale) was not applied because pre-tests with children showed that logical associations between scale and perception were missing. Before each training session, a general warm-up session (such as running on the spot, bouncing a ball, etc.) was implemented. The training itself was divided into a build-up phase and a stabilization phase. During the build-up phase (weeks 2-5), the load duration was increased from 20 to 30 seconds, and the number of laps was increased from one to two. The circuit included 7 stations (Fa. Teca S.r.l., exercises: squats, seated row, overhead press, pullover, chest press, scott curls, and back pulldown; see Faigenbaum and Westcott (2000)).

\subsection{Statistical analysis}

First, the data was checked for variance homogeneity and normal distribution. In line with the distribution, the independent t-test was applied for normally distributed parameters and the Mann-Whitney-U test was applied for nonnormally distributed parameters for group comparisons. Within an array of questions, the response frequencies were added up. The questionnaire was evaluated in terms of points, response frequencies, and each question. Fisher's exact test was applied to check frequency differences among the groups. Pre-post differences in response frequencies were validated by the McNemar test. The significance level was measured at 5\%. The test power was determined post-hoc with G*Power Version 3.1.3 (Faul, Erdfelder, Lang, \& Buchner, 2007). The effect size in the pre-post design was calculated by Cohen's d (Cohen, 1969).

\section{Results}

\subsection{Motor performance}

In the pre-post comparison, significant increases were evident in both groups for push-ups (Figure 1). The intervention group achieved a significant increase $(\mathrm{d}=1.4 ; P<0.01)$ from PRETEST $=11.7 \pm 2.5(\mathrm{Z}=103.2 \pm 7)$ to POSTTEST $=16.2 \pm 3.8$ $(Z=114.7 \pm 9)$. The control group exhibited significant improvements from PRETEST $=9.9 \pm 3.5$ ( $Z=101.8 \pm 10)$ to POSTTEST $=12.0 \pm 3.5(\mathrm{Z}=107.5 \pm 9)(\mathrm{d}=0.58 ; P<0.01)$. Among the groups, a significant contrast showed up in the average differences $(\mathrm{d}=0.62 ; P<0.05)$.
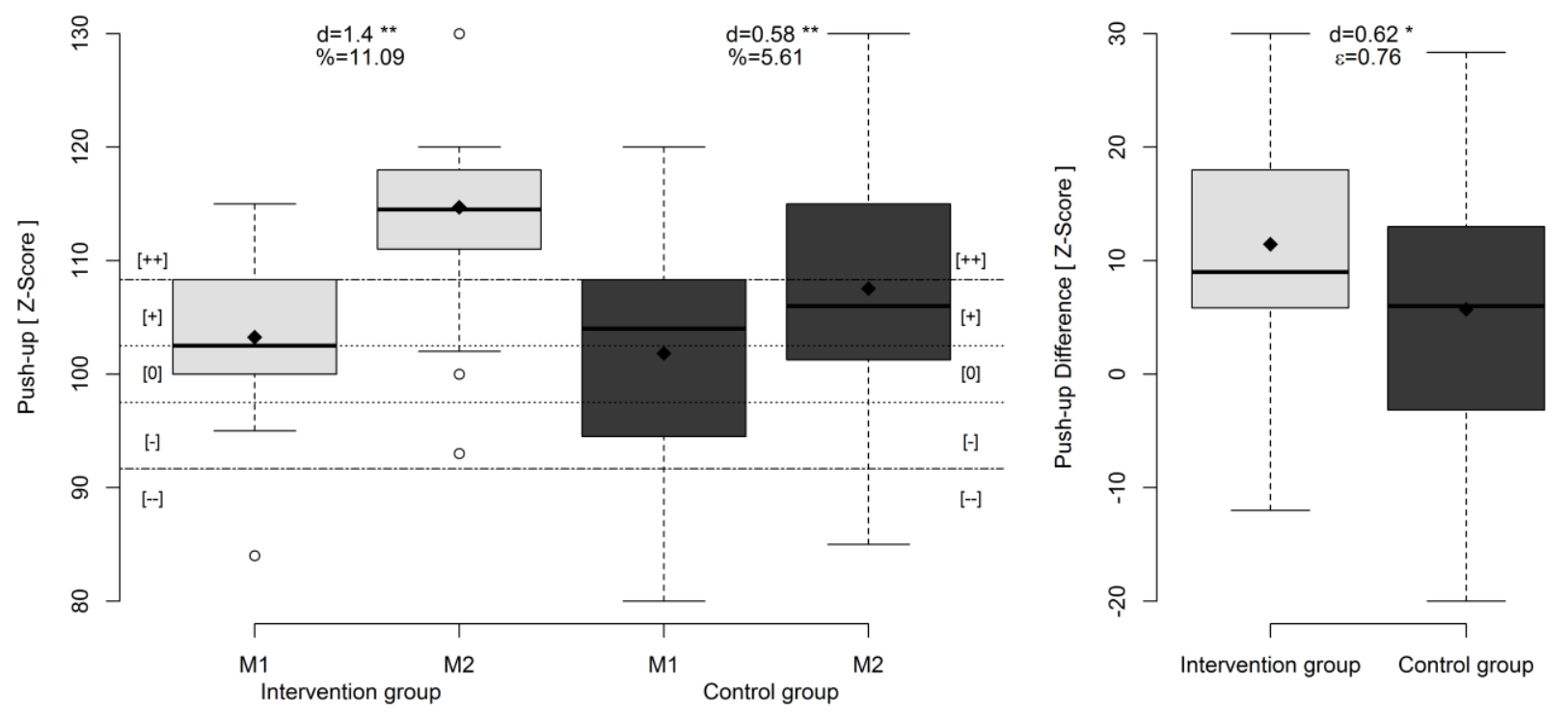

Figure 1. Box-Whisker plot push-up (++ far above average, + above average, 0 average, - below average, - - far below average $(* P<0.05, * * P<0.01, \mathrm{~d}=$ effect size, $\%=$ percentage change, $\diamond$ in box $=$ average, - in Box $=$ median, $\mathrm{M} 1=$ pre-test, $\mathrm{M} 2$ = post-test)

For the sit-ups, only the intervention group achieved a significant improvement from PRETEST=15.8 $\pm 4.3(\mathrm{Z}=90.9 \pm 8)$ to POSTTEST=20.6 $\pm 4.9(\mathrm{Z}=98.6 \pm 9)(\mathrm{d}=0.89 ; P<0.01)$ (Figure 2). The control group showed a marginal decline in the sit-up tests from PRETEST=15.9 $\pm 4.5(\mathrm{Z}=99.1 \pm 7)$ to POSTTEST=14.4 $\pm 4.2(\mathrm{Z}=96.6 \pm 6)(\mathrm{d}=-0.36 ; P<0.05)$. Highly significant differences among the groups were evident in the average differences $(\mathrm{d}=1.37 ; P<0.01)$. No significant effects were determined for standing long jump within and among the groups. 

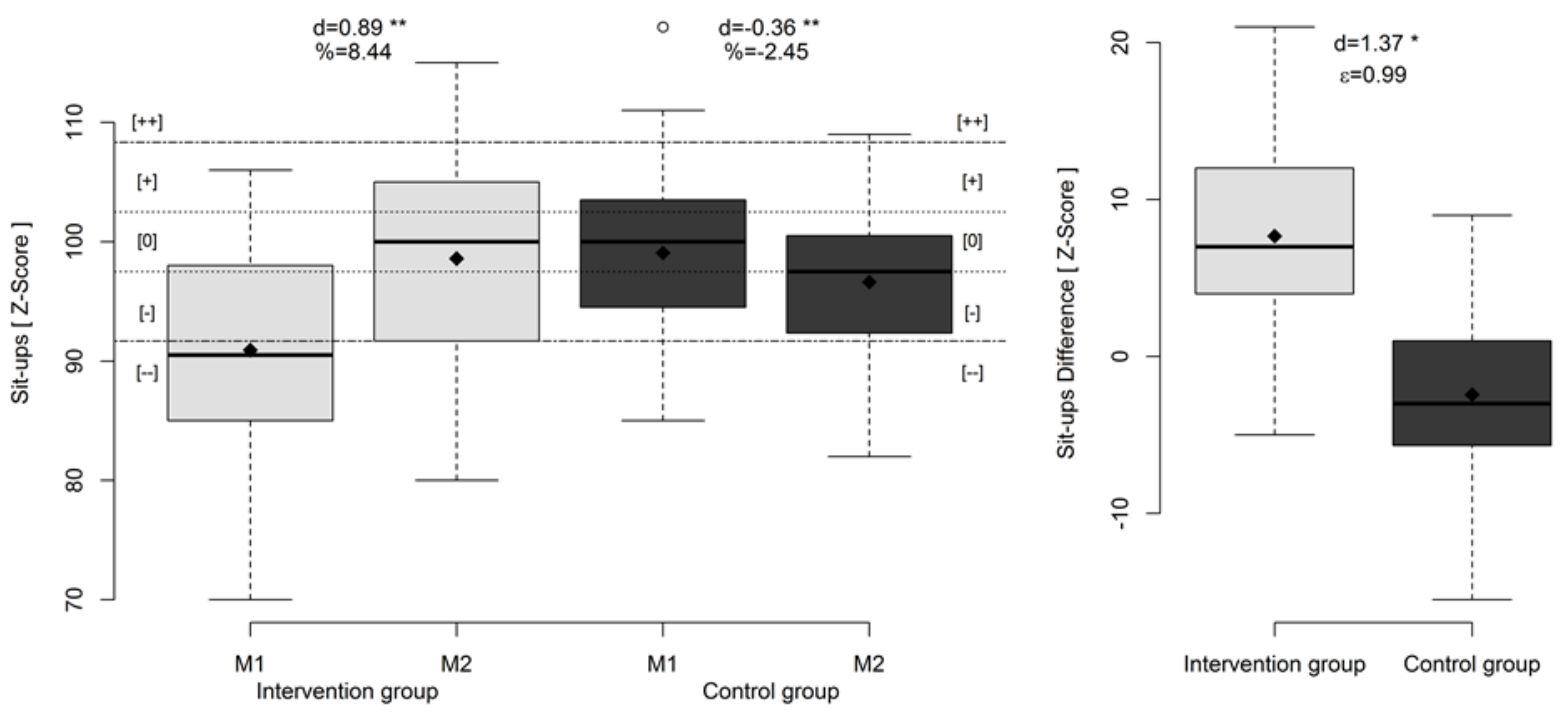

Figure 2. Box-Whisker plot sit-ups (++ far above average, + above average, 0 average, - below average, - - far below average $(* P<0.05, * * P<0.01, \mathrm{~d}=$ effect size, $\%=$ percentage change, $\diamond$ in box $=$ average, - in box $=$ median, $\mathrm{M} 1=$ pre-test, $\mathrm{M} 2$ = post-test)

\subsection{Body-related knowledge}

The total number of points in the knowledge test increased significantly in the intervention group from PRETEST (35 \pm 2 points) to POSTTEST ( $40 \pm 4$ points) $(\mathrm{d}=0.9 ; P<0.01)$. The control group exhibited a significantly reduced number of points (PRETEST $34.2 \pm 4.6$ points vs. POSTTEST $31.2 \pm 4.5$ points; $d=-0.69 ; P<0.01$ ) (Figure 3 ). Even though there were no crucial differences pertaining to the total number of points between the groups at the beginning, these differences became highly significant toward the end $(\mathrm{d}=1.58 ; P<0.01)$.
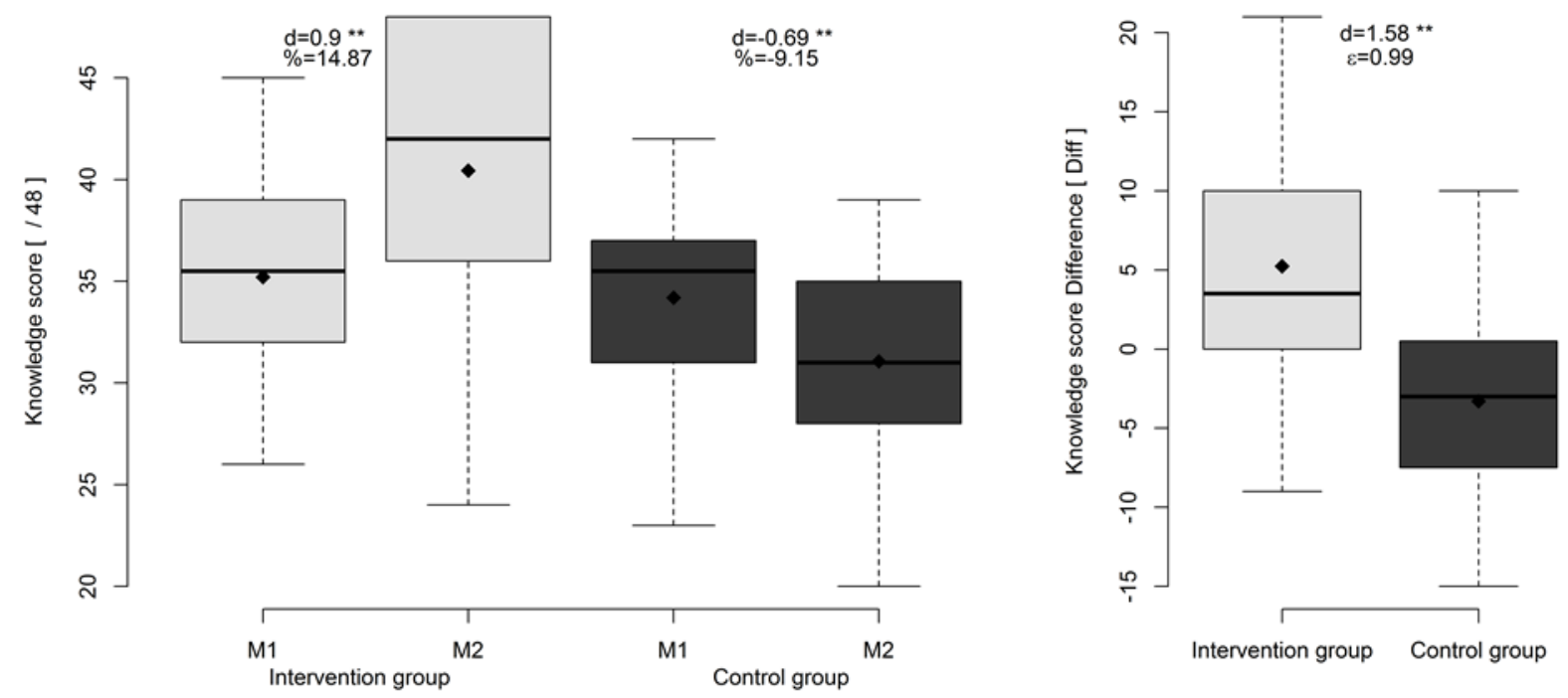

Figure 3. Box-Whisker plot knowledge score $(* P<0.05, * * P<0.01, \mathrm{~d}=$ effect size, $\%=$ percentage change, $\diamond$ in box $=$ average, - in box $=$ median, $\mathrm{M} 1=$ pre-test, $\mathrm{M} 2$ = post-test)

As the questions were divided into three arrays, they were separately evaluated based on the number of correct and wrong answers. For the pre-test, array 1 did not exhibit any significant differences in the frequency of correct and wrong responses among both groups $(P>0.05)$. In the post-test, however, the intervention group achieved a significantly higher amount of correct responses (164 correct and 6 wrong responses) than the control group (180 correct and 45 wrong responses) $(P<0.01)$. As in array 1 , there were no significant differences in array 2 in the pre-test (IG $=75$ correct and 61 wrong responses; $\mathrm{CG}=93$ correct and 95 wrong responses) among both groups in terms of the frequency of correct and wrong responses $(P>0.05)$. However, due to the more complex questions, more wrong answers were 
given in array 2 than in array 1. In the post-test, the intervention group provided a significantly higher number of correct responses (95 correct and 41 wrong responses) than the control group (65 correct responses and 115 wrong responses) $(P<0.01)$. Moreover, the control group gave more wrong responses than in the pre-test. In array 3 , the pre-test did not result in significant differences in the response frequency among both groups $(P>0.05)$. In the post-test, the correct answer was given by significantly more children of the intervention group (63 correct and 39 wrong responses) than by children of the control group (41 correct and 94 wrong responses) $(P<0.01)$. Significant increases in correct answers were evident for questions $1,2,7,9$, and 12 in the intervention group $(P<0.05)$. For questions $2,6,11$, and 12, the control group provided a significantly higher number of wrong responses $(P<0.05)$ (Figure 4$)$.

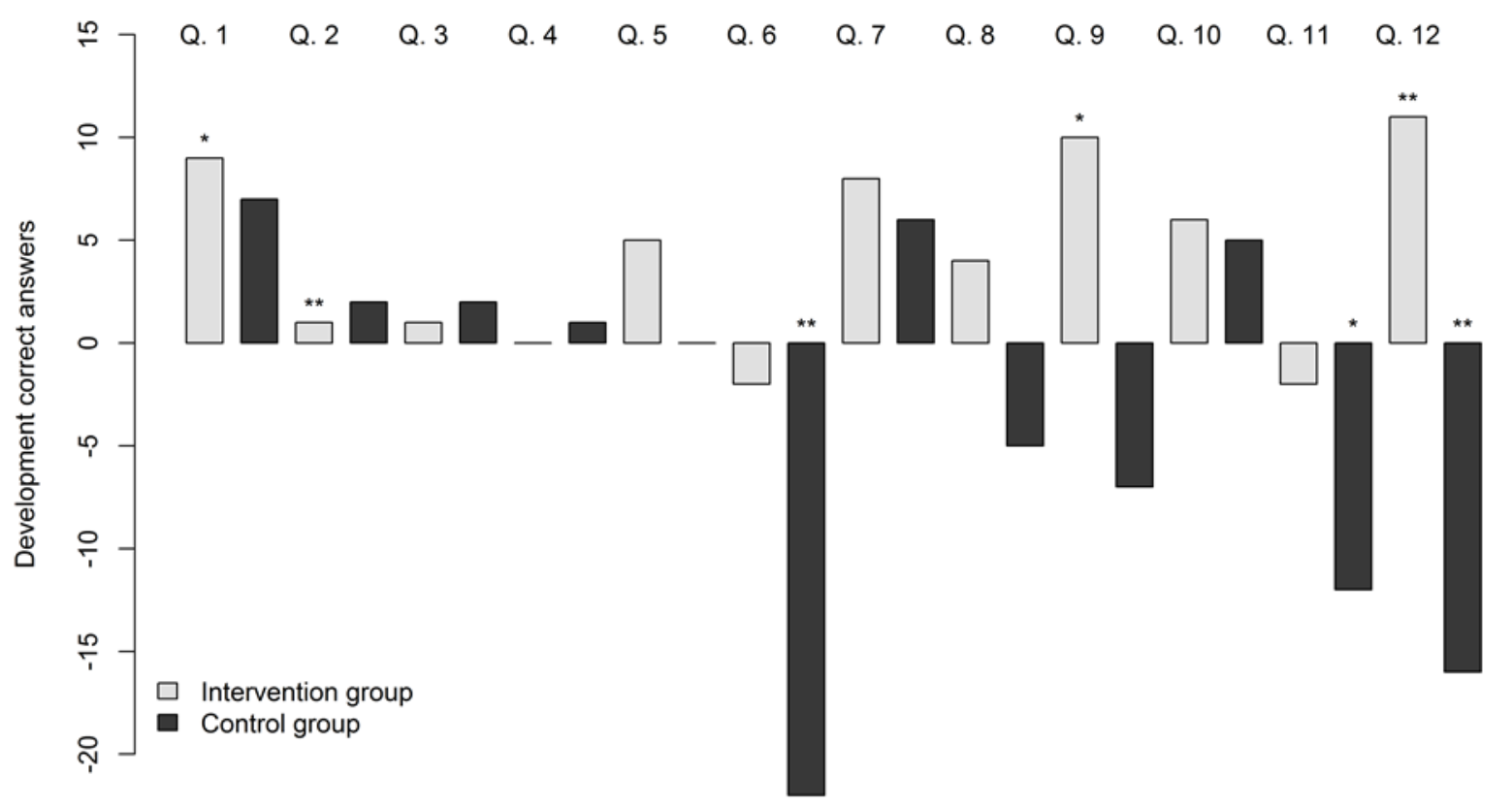

Figure 4. Change of correct and wrong responses among training group (grey) and control group (black) across all questions $(* P<0.05, * * P<0.01)$

\section{Discussion}

The results presented here as well as the training protocols applied are essentially in accordance with the recommendations found in the corresponding literature (Faigenbaum \& Westcott, 2000; Guy \& Micheli, 2001; Lloyd et al., 2014). In contrast to studies previously conducted, this study is about training with a predefined load duration and self-controlled intensity (number of repetitions, resistance). The selected organizational form of circuit training allowed the children a certain degree of exercise variation. The study's objective was to determine the effect of multi-week, selfcontrolled strength training on motor performance, while verifying the increase of body-related knowledge induced by that training.

Both groups exhibited improvement of motor performance, even though the improvement in the control group only applied to push-ups. The intervention group improved showed significantly greater effects. Maturing and learning effects cannot be entirely excluded for any of the two groups, which might explain the performance increases in the control group. In terms of body-related knowledge at the beginning of the intervention, both groups were considered homogeneous as to the number of correct and wrong answers, even though a lesser degree of knowledge might have been assumed for the control group due to its slightly lower age. The lack of movement experience might possibly have led to wrong associations in that case. Therefore, both a better functional understanding and a better idea of movement achieved through strength training seem to be apparent. This suggests that intrinsic perception in muscle tone caused by the recurrent training units promotes body-related functional understanding. Thus, it might be assumed that an increase in body-related understanding can increase overall health competence.

The lower average age in the control group might have influenced the visual imagination when answering the questions. The overall higher share of wrong responses in question arrays 2 and 3 showed that it is difficult for children to associate the knowledge about muscle functions and the interaction between training device and muscle. Therefore, in addition to the effects on motor performance, this form of physical exercise appears to be useful for body-related cognitive processes. In a way, a continued development of the body image could be seen here (Focht, 2012). Through somatic knowledge and acquired experience concerning surface structures of the body, movement amplitudes of the joints, tissue elasticity, and the body's sensor characteristics, central-nervous processes organize to generate a structuralfunctional image. It remains to be seen whether these functional competences with effects on gymnastic performance with and without equipment or in other fields of movement are associated. This knowledge could be applied in the 
further ontogenesis of children for targeted preventive movement. In the entire course of the intervention, no intervention-caused injuries occurred. This fortifies the statements found in literature about strength training for children as being relatively safe (Faigenbaum \& Myer, 2010).

\section{Conclusion}

Concluding, it can be stated that self-control of resistance and number of repetitions is possible and can be considered effective in terms of strength increase for children attending primary school. Moreover, perception processes seem to have been sensitized, which can positively influence health competence at an early age already. The conception of movement and muscles and/or muscles exercises seems to be difficult for children of this age. These complex functions and effects should be learned in primary school. Possible interventions using resistance training may be an important basis for developing health competence. Much more detailed examinations are recommended in order to fortify these sport-pedagogic demands and to verify them in terms of their effectiveness.

\section{Acknowledgement}

The authors sincerely thank the primary school students for study participating.

\section{Conflict of interest}

No conflicts of interest as well as none financial interests and relationships, patents, fees, or support by companies exist.

\section{References}

Behringer, M., vom Heede, A., Yue, Z., \& Mester, J. (2010). Effects of resistance training in children and adolescents: A meta-analysis. Pediatrics, 126(5), e1199-e1210. doi: 10.1542/peds.2010-0445

Borg, G. (1985). Psychophysical studies of effort and exertion: some historical, theoretical and empirical aspects. In G. Borg \& D. Ottoson (Eds.), The perception of exertion in physical work (pp. 3-12). Basingstroke: Macmillan.

Bös, K., Schlenker, L., Büsch, D., Lämmle, L., Müller, H., Oberger, J., . . Tittlbach, S. (2009). Deutscher Motorik-Test 6-18 (DMT6-18) (Vol. Schriften der Deutschen Vereinigung für Sportwissenschaft, Bd. 186). Hamburg: Czwalina Verlag.

Christou, M., Smilios, I., Sotiropoulos, K., Volaklis, K., Pilianidis, T., \& Tokmakidis, S. P. (2006). Effects of resistance training on the physical capacities of adolescent soccer players. Journal of Strength and Conditioning Research, 20(4), 783-791. doi: 10.1519/r-17254.1

Cohen, J. (1969). Statistical power analysis for the behavioral sciences. New York, London: Academic Press.

Faigenbaum, A. D., Kraemer, W. J., Blimkie, C. J. R., Jeffreys, I., Micheli, L. J., Nitka, M., \& Rowland, T. W. (2009). Youth resistance training: Updated position statement paper from the National Strength and Conditioning Association. Journal of Strength and Conditioning Research, 23(Supplement), S60-S79.

Faigenbaum, A. D., McFarland, J. E., Keiper, F. B., Tevlin, W., Ratamess, N. A., Kang, J., \& Hoffman, J. R. (2007). Effects of a short-term plyometric and resistance training program on fitness performance in boys age 12 to 15 years. Journal of Sports Science \& Medicine, 6(4), 519-525.

Faigenbaum, A. D., Milliken, L. A., Loud, R. L., Burak, B. T., Doherty, C. L., \& Westcott, W. L. (2002). Camparison of 1 and 2 days per week of strength training in children. Research Quarterly for Exercise and Sport, 73, 416-424.

Faigenbaum, A. D., \& Myer, G. D. (2010). Resistance training among young athletes: safety, efficacy and injury prevention effects. British Journal of Sports Medicine, 44(1), 56-63. doi: 10.1136/bjsm.2009.068098

Faigenbaum, A. D., \& Westcott, W. L. (2000). Strength and power for young athletes. Champaign, Illinois: Human Kinetics.

Falk, B., \& Tenenbaum, G. (1996). The effectiveness of resistance training in children. A meta-analysis. Sports Medicine, 22(3), 176-186.

Faul, F., Erdfelder, E., Lang, A.-G., \& Buchner, A. (2007). G*Power 3: A flexible statistical power analysis program for the social, behavioral, and biomedical sciences. Behavior Research Methods, 39(2), 175-191. doi: 10.3758/BF03193146

Focht, B. C. (2012). The utility of applying social cognitive theories of behavier to explain resistance exercise participation. In J. Gießing, M. Fröhlich, \& R. Rößler (Eds.), Current results of strength training research. Various aspects on fitness and performance (Vol. Third Volume pp. 39-48). Göttingen: Cuvillier Verlag.

Fogelholm, M. (2010). Physical activity, fitness and fatness: relations to mortality, morbidity and disease risk factors. A systematic review. Obesity Reviews, 11(3), 202-221. doi: 10.1111/j.1467-789X.2009.00653.x

Granacher, U., Goesele, A., Roggo, K., Wischer, T., Fischer, S., Zuerny, C., . . . Kriemler, S. (2011). Effects and mechanisms of strength training in children. International Journal of Sports Medicine, 32(5), 357-364. doi: 10.1055/s0031-1271677 
Guy, J. A., \& Micheli, L. J. (2001). Strength training for children and adolescents. Journal of the American Academy of Orthodaedic Surgeons, 9(1), 29-36.

Harriss, D. J., \& Atkinson, G. (2011). Update--Ethical standards in sport and exercise science research. International Journal of Sports Medicine 32(11), 819-821. doi: 10.1055/s-0031-1287829

Ingle, L., Sleap, M., \& Tolfrey, K. (2006). The effect of a complex training and detraining programme on selected strength and power variables in early pubertal boys. Journal of Sports Sciences, 24(9), 987-997. doi: $10.1080 / 02640410500457117$

Klein, M., Fröhlich, M., \& Emrich, E. (2013). Motor performance and bodyweight of children and adolescents in Saarland - Status quo. European Journal of Sport Science, 13(3), 280-289. doi: 10.1080/17461391.2011.635702

Klein, M., Fröhlich, M., Pieter, A., \& Emrich, E. (2015). Socio-economic status and motor performance of children and adolescents. European Journal of Sport Science, 1-8. doi: 10.1080/17461391.2014.1001876

Lillegard, W. A., Brown, E. W., Wilson, D. J., Henderson, R., \& Lewis, E. (1997). Efficacy of strength training in prepubescent to early postpubescent males and females: effects of gender and maturity. Pediatric Rehabilitation, 1(3), 147-157.

Lloyd, R. S., Faigenbaum, A. D., Stone, M. H., Oliver, J. L., Jeffreys, I., Moody, J. A., Myer, G. D. (2014). Position statement on youth resistance training: the 2014 International Consensus. British Journal of Sports Medicine, 48(7), 498-505. doi: 10.1136/bjsports-2013-092952

Metcalf, B. S., Hosking, J., Jeffery, A. N., Voss, L. D., Henley, W., \& Wilkin, T. J. (2011). Fatness leads to inactivity, but inactivity does not lead to fatness: a longitudinal study in children (EarlyBird 45). Archives of Disease in Childhood, 96(10), 942-947. doi: 10.1136/adc.2009.175927

Payne, V. G., Morrow, J. R., Johnson, L., \& Dalton, S. N. (1997). Resistance training in children and youth: a metaanalysis. Research Quarterly for Exercise and Sport, 68(1), 80-88.

Pfeifer, K., Sudeck, G., Geidl, W., \& Tallner, A. (2013). Bewegungsförderung und Sport in der Neurologie Kompetenzorientierung und Nachhaltigkeit. Neurologie und Rehabilitation, 19 (1), 7-19.

Raj, M. (2012). Obesity and cardiovascular risk in children and adolescents. Indian Journal of Endocrinology and Metabolism, 16(1), 13-19. doi: 10.4103/2230-8210.91176

Shariat, A., Shariat, A., Abedi, A., \& Bahri, S. B. M. (2014). Physical activity as a prescription for the children with cerebral palsy. Russian Open Medical Journal, 3(1), 1-4. doi: 10.15275/rusomj.2014.0108

Westcott, W. L., Tolken, J., \& Wessner, B. (1995). School-based conditioning programs for physically unfit children. Strength and Conditioning, 17(2), 5-9. 